\title{
Ethicists resign to protest ClHR stance
}

$\mathrm{T}$ wo medical ethicists have resigned from their advisory positions with the Canadian Institutes of Health Research (CIHR), marking the latest development in a long-simmering dispute over the institute's lack of leadership with ethics expertise.

Françoise Baylis, who holds the Canada Research Chair in Bioethics and Philosophy at Dalhousie University, Halifax, and Chris Kaposy, a professor of health care ethics at Memorial University of Newfoundland, St. John's, both issued strongly worded letters accompanying their respective departures on June 16 and 24.

In those letters, which can be found at impactethics.ca, Baylis derided CIHR as "an organization that openly and persistently demonstrates disrespect for ethics expertise," while Kaposy took aim at the agency's chief scientific officer and vice-president, research. "The person now in charge of ethics at CIHR, Dr. Jane Aubin, has no background in ethics as an academic or clinical pursuit," he wrote. "I find this insulting."

The concept of "ethics expertise" lies at the heart of the complaint, according to Baylis, Kaposy and their colleagues across Canada, who regularly cite a definition in CIHR's 2013 task force report recommending CIHR create a new position of vice-president of ethics. The report states that the VP "must have the knowledge, skills and experience to elevate the status of ethics to a position within the organization ... and to develop and execute innovative, world-class programming in research ethics and related research policy." Furthermore, the VP "should be recognized nationally and internationally as a leading scholar and researcher in ethics."

Aubin, for her part, has made no claim to specific credentials in the field of ethics, something she acknowledged publicly following a presentation to the annual meeting of the Canadian Bioethics Society in Vancouver at the end of May. Her career has included studies in molecular biology and biochemistry, as well as academic administrative posi-

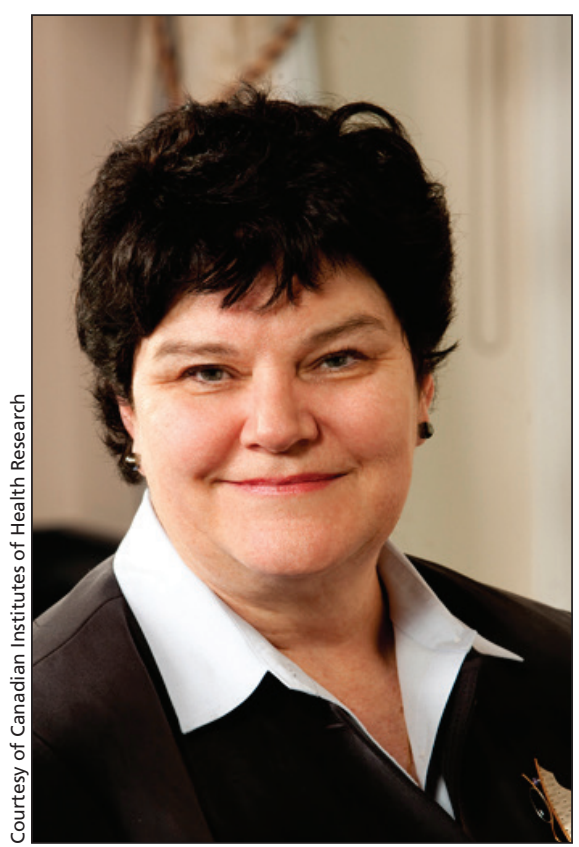

Among complaints from ethicists is that VP Ethics Dr. Jane Aubin (pictured above) has no academic expertise in the field.

tions at the University of Toronto and four years as scientific director of CIHR's Institute of Musculoskeletal Health and Arthritis.

Since assuming her current post in 2011, Aubin has cast herself as "Champion of Ethics." She says similar arrangements exist at comparable bodies in the United Kingdom, European Union, Australia and United States, where executives provide ethics leadership without having any particular expertise in this area. Aubin also suggests that her role draws on expertise from others at CIHR.

"We're not relying on a single leader or a single committee," she says. "Because we have multiple levels and multiple committees from which we get advice from ethics experts, we're well out there at the front of the pack."

Aubin notes that CIHR receives this advice through mechanisms such as institute advisory boards (IABs). There are 13 of these boards - one for each of the organization's institutes - made up of representatives not only from academia, but also doctors, patients, citizens and members of other organizations. Each board also features expertise centred on an "ethics designate," the post formerly held by Baylis at the IAB for the Institute of Gender and Health and by Kaposy at the IAB for the Institute of Infection and Immunity.

Their departure highlights complaints about Aubin's ethical expertise and qualifications that are part of a larger, ongoing critique mounted by specialists in the field who have spent years insisting that CIHR has been shirking the health ethics mandate written directly into the Act of Parliament that created this agency in 2000 .

In response, CIHR established a task force in 2012 to judge how well that mandate was being met. Its report recommended that the new VP of ethics should be a "strong individual" whose professional standing with respect to ethics would be analogous to the authority expected of any CIHR scientific director.

CIHR management subsequently declared the prospect of a new VP position as "neither operationally feasible nor ideal," offering instead to assign the role of "champion" to Aubin's existing position and broaden the membership of the Governing Council's Standing Committee on Ethics.

That option does not sit well with Daryl Pullman, a task force member and professor of medical ethics at Memorial University of Newfoundland. "Being a leader in any discipline means having a certain amount of expertise in that area." — Tim Lougheed, Ottawa, Ont.

CMAJ 2014. DOI:10.1503/cmaj.109-485 